\title{
SOCIAL DESIGN THINKING APLICADO AO ENSINO EM ENGENHARIA DE PRODUÇÃO
}

DOI: 10.37702/2175-957X.COBENGE.2021.3374

CARLOS ROBERTO FRANZINI FILHO - crfilho@anhembi.br

Universidade Anhembi Morumbi

Rua Ibatiba 235

09220-608 - Santo André - SP

Adiloderne Nogueira Souza Filho - adilo.nogueira@gmail.com

Universidade Anhembi Morumbi

Passagem José Rossi 31

07130-430 - Guarulhos - SP

ALEXANDRE TAVARES SOARES - atsoares@anhembi.br

Universidade Anhembi Morumbi

Resumo: Em razão da COVID-19, a população global mergulhou em uma situação emergencial e nesse contexto, a Organização Mundial da Saúde (OMS) declarou pandemia em março de 2020 e, seguindo suas orientações, o Conselho Nacional de Saúde (CNS) recomendou medidas de isolamento social para evitar a propagação do vírus e dessa forma a sociedade brasileira foi afetada como um todo, configurando o que hoje é chamado de "novo normal". Diante deste cenário, a fome se fez presente entre as famílias brasileiras com menor renda per capita trazendo algum grau de insegurança alimentar para mais da metade dos domicílios brasileiros. Por outro lado, a discussão em torno de iniciativas para combater a fome têm sido abordadas, ainda que de forma tímida, dentro das Instituições de Ensino Superior (IES). A partir das considerações iniciais, este artigo propõe-se a descrever a aplicação do Design Thinking para a construção de hortas verticais pelos discentes e docentes inscritos no projeto de extensão universitária da IES. Para atingir ao objetivo proposto, realizou-se um estudo de caso a partir de um projeto de extensão universitária onde o Design Thinking foi aplicado na construção de hortas verticais sustentáveis a serem ofertadas para famílias em situação de vulnerabilidade. Espera-se que as informações geradas a partir da realização deste trabalho, possam contribuir como um instrumento de incentivo 
para a agricultura sustentável conforme previsto no objetivo \#2 da Agenda 2030 da ONU. Sugere-se a replicação desta iniciativa em outros cursos ofertados pela IES, bem como para outras IES, públicas ou privadas.

Palavras-chave: Ensino em Engenharia. Agricultura sustentável. Hortas Verticais. Responsabilidade socioambiental. 


\section{SOCIAL DESIGN THINKING APLICADO AO ENSINO EM ENGENHARIA DE PRODUÇÃO}

\section{INTRODUÇÃO}

Em razão da COVID-19, a população global mergulhou em uma situação emergencial jamais vista nos tempos modernos. Dentro dessa abordagem, a Organização Mundial da Saúde (OMS, 2020) declarou pandemia em março de 2020 e, seguindo suas orientações, o Conselho Nacional de Saúde (CNS, 2020) recomendou medidas de isolamento social para evitar a propagação do vírus e com isso, a sociedade brasileira foi afetada como um todo (DONTHU; GUSTAFSSON, 2020), configurando o que hoje é chamado de "novo normal".

Como forma de socorrer a população carente e em situação de vulnerabilidade, o Governo Federal propôs um Auxílio Emergencial no valor de $\mathrm{R} \$ 600,00$ durante seis meses e a distribuição deste encerrou-se no mês de dezembro de 2020. Diante deste cenário, a fome se fez presente entre as famílias brasileiras com menor renda per capita trazendo algum grau de insegurança alimentar para mais da metade dos domicílios brasileiros $(55,2 \%)$, ou seja, mais de 116,8 milhões de pessoas de acordo com dados apurados pelo "Inquérito Nacional sobre Insegurança alimentar no Contexto da Pandemia da Covid 19 no Brasil" (2021).

A discussão em torno de iniciativas para combater a fome têm sido abordadas, ainda que de forma tímida, dentro das Instituições de Ensino Superior (IES). De acordo com a Resolução do Ministério da Educação ( $\mathrm{n}^{\circ}$ 7/2018), a extensão universitária é um processo interdisciplinar, educativo, cultural, científico e político, por meio do qual se promove uma interação que transforma não apenas a academia, mas também os setores sociais com os quais ela interage (BRASIL, 2018). Dentro dessa abordagem a IES convoca anualmente sua comunidade acadêmica para apresentar propostas de Projetos de Extensão Universitária que envolvam o corpo docente e discente, gerando resultados para a academia, sociedade e contribuindo para o cumprimento da missão institucional de "Expandir o acesso à educação superior de qualidade, assegurando a formação de cidadãos e profissionais empreendedores, capazes de fazer do mundo um lugar melhor".

Atualmente, observa-se uma força tarefa da ONU a partir de sua Agenda 2030 que prevê em seu objetivo de desenvolvimento sustentável número 2 (ODS \#2), acabar com a fome, alcançar a segurança alimentar e melhoria da nutrição e promover a agricultura sustentável. Dentro deste contexto, as Instituições de Ensino Superior podem contribuir com a formação de cidadãos pensantes, críticos e reflexivos, além de promoverem educação e desenvolvimento sustentável em suas ações.

O Design Thinking é uma metodologia estruturada de solução de problemas ensinada em sala de aula no curso de Engenharia de Produção para desenvolver produtos, serviços e modelos de negócios inovadores. Essa abordagem permite o desenvolvimento de habilidades e processos utilizados por designers, para que assim, cada indivíduo consiga contribuir com soluções inovadoras de problemas complexos (VIEIRA et al., 2010). Nesse contexto, observa-se uma oportunidade com a oferta de hortas verticais sustentáveis para famílias em situação de vulnerabilidade como forma de promover a agricultura sustentável em médio e longo prazo como previsto no ODS \# 2. Esta iniciativa também pode contribuir para que os discentes adquiram conhecimentos e habilidades necessárias para promover o desenvolvimento sustentável, estilo de vida sustentável,

A partir das considerações iniciais, este artigo propõe-se a descrever a aplicação do Design Thinking para a construção de hortas verticais pelos discentes e docentes inscritos no projeto de extensão universitária da IES. 


\section{REFERENCIAL TEÓRICO}

O Design Thinking é uma abordagem estruturada para a solução de problemas com o objetivo de desenvolver produtos, serviços e modelos de negócios inovadores segundo Hehn et al (2019). Para Brenner et al. (2016). A Figura 1 apresenta as etapas para a implementação do Design Thinking onde observa-se três macro etapas: compreender, explorar e materializar.

Figura 1 - Etapas para a abordagem Design Thinking.
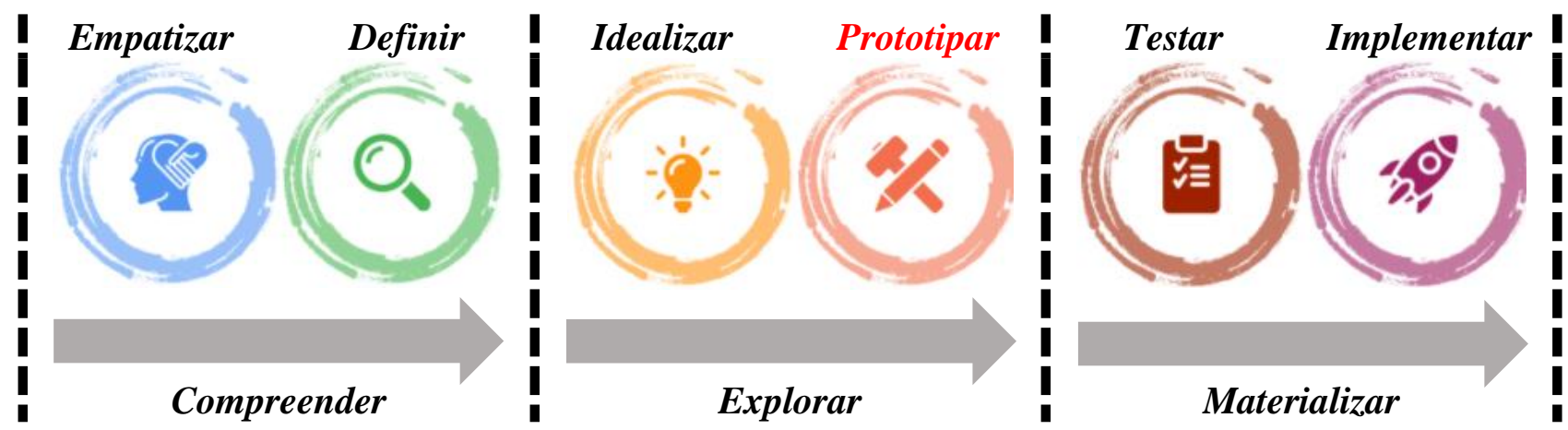

Fonte: Adaptado de Brenner et al (2016).

O Quadro 1 apresenta a descrição para cada uma das etapas apresentadas na Figura 1. Cada uma das etapas abrange um conjunto de ferramentas, porém, caso necessário, a equipe pode aplicar uma ferramenta fora da ordem caso julgue necessário (IDEO, 2012).

Quadro 1 - Descrição das etapas Design Thinking.

\begin{tabular}{|c|c|c|}
\hline \multicolumn{2}{|c|}{ Etapas } & Descrição \\
\hline \multirow[b]{2}{*}{ Compreender } & Empatizar & $\begin{array}{l}\text { A etapa "Empatizar" consiste em observar o mundo pelos olhos do } \\
\text { usuário. Nesta etapa é utilizado o mapa de empatia para conhecer melhor } \\
\text { o cliente (conhecer seus sentimentos, dores e necessidades). }\end{array}$ \\
\hline & Definir & $\begin{array}{l}\text { A etapa "Definir o problema" consiste na identificação do problema, ou } \\
\text { seja, descreve o problema no qual deve ser resolvido. A arte de encontrar } \\
\text { e descrever o problema de forma clara é um grande desafio, pois é a } \\
\text { partir do problema que toda metodologia se inicia, sendo assim, } \\
\text { compreender bem o problema é de grande importância. }\end{array}$ \\
\hline \multirow{2}{*}{ Explorar } & Idealizar & $\begin{array}{l}\text { A etapa "Idealizar" consiste na etapa onde as ideias são geradas. Nesta } \\
\text { etapa a equipe é incentivada a encontrar ideias de solução por meio de } \\
\text { brainstorming. }\end{array}$ \\
\hline & Prototipar & $\begin{array}{l}\text { A etapa "Prototipar", tem como objetivo criar protótipos que possam ser } \\
\text { testados na próxima etapa com os clientes. Estes protótipos podem ser } \\
\text { feitos de madeira, maquetes papel, dentre outras. }\end{array}$ \\
\hline \multirow[t]{2}{*}{ Materializar } & Testar & $\begin{array}{l}\text { A etapa "Testar" consiste em testar os protótipos com rigor. Embora esta } \\
\text { seja a fase final, o Design Thinking é interativo: as equipes costumam } \\
\text { usar os resultados para redefinir um ou mais problemas adicionais. } \\
\text { Assim, você pode retornar aos estágios anteriores para fazer mais } \\
\text { interações, alterações e refinamentos - para encontrar ou descartar } \\
\text { soluções alternativas. }\end{array}$ \\
\hline & Implementar & $\begin{array}{l}\text { A fase "Implementar", tem como objetivo colocar em prática as soluções } \\
\text { obtidas com as etapas anteriores. Significa materializar e tocar a vida do } \\
\text { usuário final. }\end{array}$ \\
\hline
\end{tabular}

Fonte: Adaptado de Brenner et al (2016). 


\section{METODOLOGIA}

Para atingir ao objetivo proposto com a realização deste trabalho, realizou-se um estudo de caso exploratório a partir do Projeto de Extensão Universitária (PEU) proposto pela IES. De acordo com Nakano (2012), o estudo de caso é resultante de uma pesquisa profunda sobre determinado fato, que permite o conhecimento mais detalhado do objetivo da pesquisa, neste caso, o objetivo da pesquisa é descrever a aplicação do Design Thinking para a construção de hortas verticais pelos discentes e docentes inscritos no PEU.

A Figura 2 apresenta as técnicas e ferramentas aplicadas para as etapas do Design Thinking para a realização do PEU para a construção das hortas verticais sustentáveis.

Figura 2 - Técnicas \& Ferramentas aplicadas nas etapas do Design Thinking.

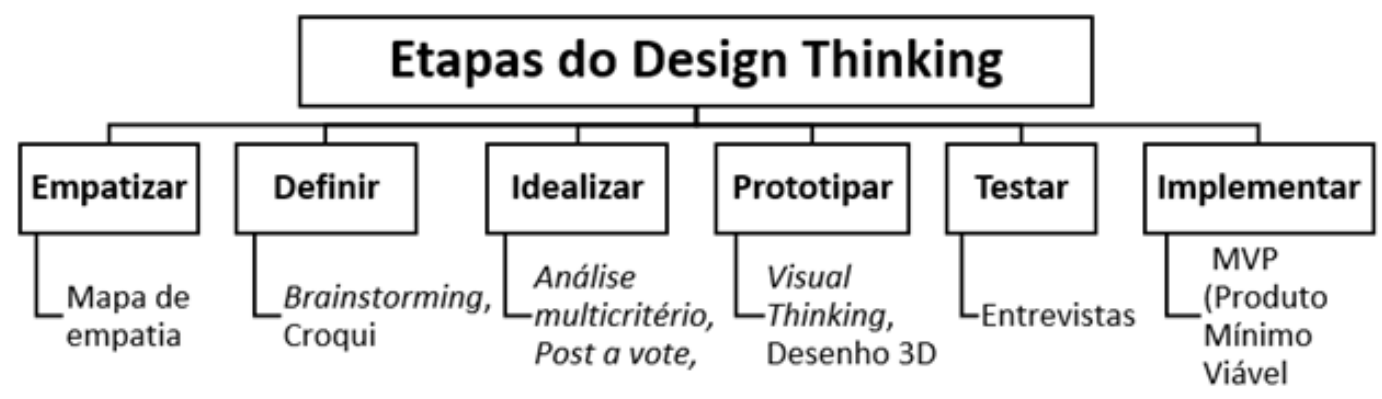

Fonte: Elaborado pelos autores (2021).

$\mathrm{Na}$ etapa empatizar, foi elaborado o mapa de empatia a partir de 6 questões propostas com o objetivo de identificar as famílias interessadas em receber a horta vertical ofertada pelo PEU da IES e as suas expectativas.

Para a etapa definir, foi elaborado os croquis e discutidas todas as ideias sugeridas pelos integrantes dos grupos via brainstorming (técnica de discussão em grupo). A abordagem Design Thinking incentiva a expressão de diferentes pensamentos e possui tolerância a erros.

Já na etapa idealizar buscou-se juntar os pensamentos analítico e intuitivo para classificar a partir de uma análise multicritério as ideias como: novas, uteis e viáveis para a construção da horta vertical a ser ofertada pelo PEU.

A prototipagem foi a quarta etapa do Design Thinking e nesta etapa foram propostas diferentes modelos de hortas verticais construídas a partir de garrafas PET descartáveis. $O$ Visual Thinking (VT) foi a técnica aplicada para construção de protótipos rápidos e as vezes feios para aprendizagem sobre a montagem das hortas verticais. As etapas para o Visual Thinking são: 1) Olhe (O que eu estou olhando?), 2) Veja (O que eu estou vendo?), 3) Imagine (Como posso manusear estes padrões?), 4 Apresente (Isso foi o que eu vi e acho que é esse o significado).

Para a etapa testar, foram realizadas entrevistas com perguntas abertas e fechadas feitas às famílias interessadas em receber as hortas verticais. A partir dos resultados apurados, foram implementadas melhorias nos protótipos das hortas a serem ofertadas pelo PEU.

$\mathrm{Na}$ última etapa (implementar), foi aplicado o produto mínimo viável, que normalmente é utilizado para testar um negócio, pois traz as informações necessárias para a tomada de decisões no que diz respeito a viabilidade econômica, principalmente em encontrar a melhor e mais barata versão da horta vertical.

Todas as técnicas e ferramentas aplicadas durante as etapas do Design Thinking, tiveram como objetivo prover o máximo de aprendizado sobre hortas verticais para os discentes e docentes em um curto espaço de tempo para a realização do PEU. 


\section{ANÁLISE \& DISCUSSÃO DOS RESULTADOS}

Os Projetos de Extensão Universitária (PEU) da IES correspondem a um conjunto de atividades de caráter educativo, social, cultural, científico ou tecnológico, com objetivos específicos e prazos determinados. Os projetos são aprovados, via edital anual, com inscrições de docentes e discentes, com duração de 12 meses. As suas ações visam promover a interação transformadora entre a comunidade acadêmica e a sociedade. Os projetos devem estar vinculados à pelos menos dois Programas Institucionais de Extensão Universitária, conforme detalhamento na Política Institucional de Extensão Universitária.

O Projeto Social de Extensão Universitária Design Thinking aplicado a hortas verticais teve início no primeiro semestre do ano de 2021 . Houve 27 discentes inscritos divididos em 5 grupos respectivamente.

A Figura 3 ilustra o processo de desenvolvimento das hortas verticais com a aplicação da metodologia Design Thinking.

Figura 3 - Etapas do desenvolvimento de hortas verticais com a aplicação da metodologia Design Thinking.

\begin{tabular}{|c|c|c|c|c|c|}
\hline $\begin{array}{l}\text { Empatizar } \\
\text { - Entrevistar } \\
\text { as famílias } \\
\text { interessadas } \\
\text { na horta } \\
\text { vertical e } \\
\text { criar o mapa } \\
\text { de empatia. }\end{array}$ & $\begin{array}{l}\text { Definir } \\
\text { - Definir os } \\
\text { requisitos } \\
\text { para a } \\
\text { construção } \\
\text { da horta } \\
\text { vertical } \\
\text { sustentável }\end{array}$ & $\begin{array}{l}\text { Idealizar } \\
\text { - Definir como } \\
\text { será a horta } \\
\text { vertical e o } \\
\text { que será } \\
\text { plantado } \\
\text { nela. }\end{array}$ & $\begin{array}{l}\text { Prototipar } \\
\text { - Apresentar } \\
\text { os protótipos } \\
\text { gerados a } \\
\text { partir do } \\
\text { brainstorming } \\
\text { realizado nas } \\
\text { etapas } \\
\text { anteriores }\end{array}$ & \begin{tabular}{l}
\multicolumn{1}{c}{ Testar } \\
- Consultar as \\
famílias \\
interessadas \\
sobre os \\
protótipos \\
construídos e \\
captar suas \\
percepções
\end{tabular} & $\begin{array}{l}\text { Implementar } \\
\text { - Disponibilizar } \\
50 \text { hortas } \\
\text { verticais } \\
\text { sustentáveis } \\
\text { para as } \\
\text { famílias }\end{array}$ \\
\hline
\end{tabular}

Fonte: Elaborado pelos autores (2021).

\subsection{Etapa empatizar}

O mapa de empatia foi aplicado com o objetivo de conhecer melhor o perfil das famílias interessadas em receber a horta vertical sustentável a partir de 6 perguntas para conhecer seus sentimentos, dores e necessidades.

Figura 4 - Mapa de empatia para a horta vertical sustentável.

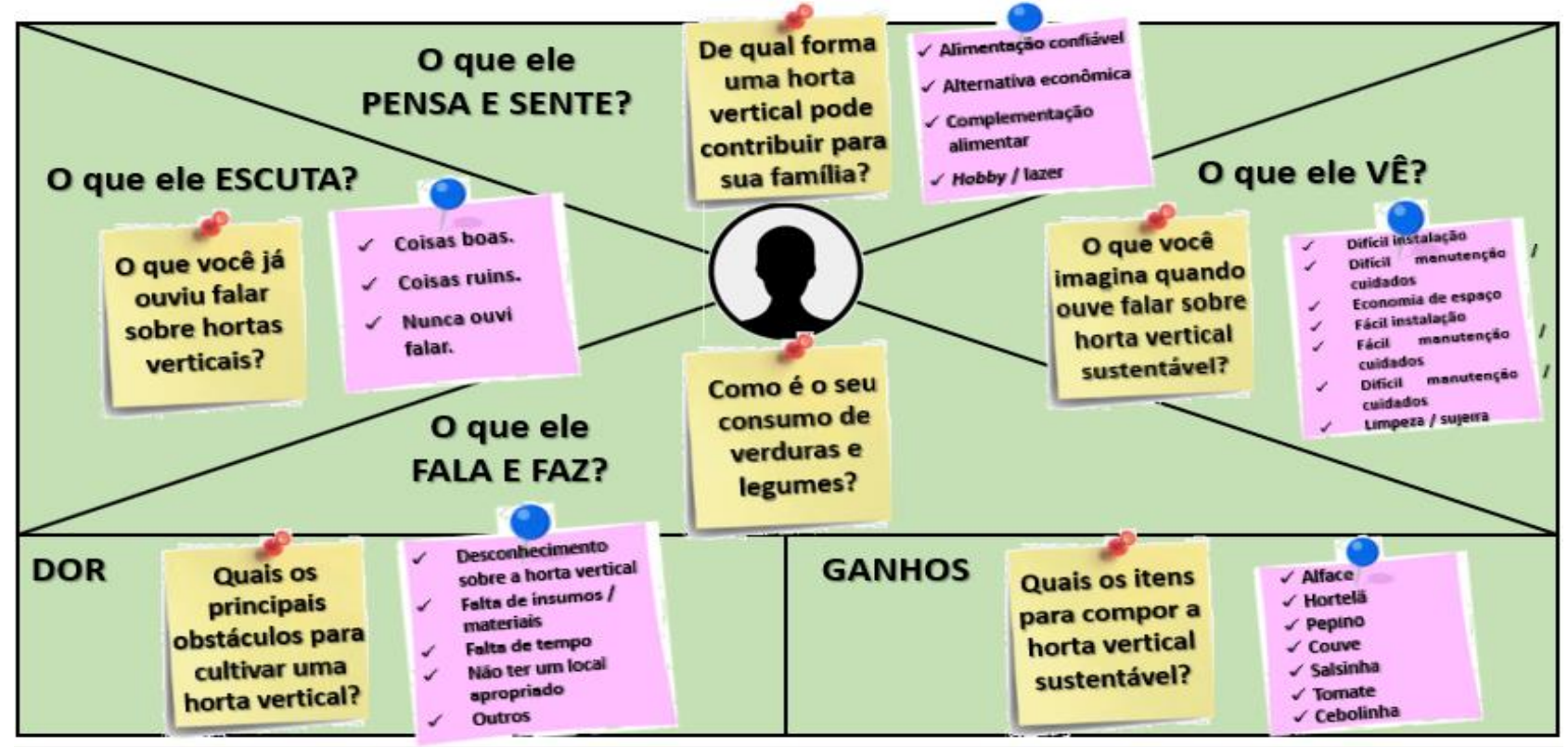

Fonte: Elaborado pelos autores (2021). 


\subsection{Etapa definir}

A partir de um brainstorming realizado com os grupos inscritos no PEU, foram definidos os requisitos para a construção das hortas verticais sustentáveis. Ficou definido a utilização de garrafas PET descartáveis de dois litros para a plantação de mudas e sementes e também a utilização de corda de varal no 5 para montagem da estrutura. Os itens sugeridos para a plantação na horta vertical estão apresentados no Quadro 2.

Quadro 2 - Itens sugeridos para cultivo na horta vertical.

\begin{tabular}{|c|c|c|}
\hline Item & $\begin{array}{c}\text { Descrição, culinária } \\
\text { e/ou benefícios }\end{array}$ & Características \\
\hline Acelga & $\begin{array}{l}\text { Muito apreciada por ser altamente nutritiva e por } \\
\text { conter propriedades medicinais benéficas para a } \\
\text { saúde, a acelga é um vegetal folhoso cultivado em } \\
\text { praticamente todas as zonas temperadas do mundo. }\end{array}$ & $\begin{array}{l}\text { Planta forte e vigorosa com folhas } \\
\text { de tamanho médio de } 25 \times 40 \mathrm{~cm} \text {. } \\
\text { Talos de aproximadamente } 10 \mathrm{~cm} \text {. } \\
\text { Ciclo: } 50 \text { a } 60 \text { dias após semeadura }\end{array}$ \\
\hline Alecrim & $\begin{array}{l}\text { O alecrim é uma erva aromática apreciada na } \\
\text { preparação de aves, carnes, salsichas, linguiças e } \\
\text { batatas assadas. }\end{array}$ & $\begin{array}{l}\text { As folhas são lineares e aromáticas, } \\
\text { medindo de } 1,4 \text { a } 4 \text { centímetros de } \\
\text { comprimento. Ciclo: } 50 \text { a } 60 \text { dias } \\
\text { após semeadura }\end{array}$ \\
\hline $\begin{array}{l}\text { Alface } \\
\text { crespa }\end{array}$ & $\begin{array}{l}\text { A alface contém ferro, mineral com importante papel } \\
\text { no transporte de oxigênio no organismo. Contém } \\
\text { fibras, que auxiliam na digestão e no bom } \\
\text { funcionamento do intestino. }\end{array}$ & $\begin{array}{l}\text { Planta grande de coloração verde- } \\
\text { clara, não forma cabeça de } \\
\text { tamanho médio de. } 30 \text { a } 40 \mathrm{~cm} \text {. } \\
\text { Ciclo: } 60 \text { a } 65 \text { dias após semeadura. }\end{array}$ \\
\hline $\begin{array}{c}\text { Alface } \\
\text { lisa }\end{array}$ & $\begin{array}{l}\text { A alface lisa é uma das variedades de alface que tem } \\
\text { como principal característica suas folhas lisas, soltas } \\
\text { e abertas. Pelo seu sabor mais suave, rende uma boa } \\
\text { salada! Sem falar que é rica em vitaminas e minerais. }\end{array}$ & $\begin{array}{l}\text { Planta forte, compacta, com folhas } \\
\text { macias, não forma cabeça bem } \\
\text { fechada de tamanho médio de } 25 x \\
30 \mathrm{~cm} \text {. Ciclo: } 70 \text { a } 75 \text { dias após } \\
\text { semeadura. }\end{array}$ \\
\hline Cebolinha & $\begin{array}{l}\text { A cebolinha é muito benéfica para a saúde, sendo rica } \\
\text { em nutrientes, antioxidantes e pouco calórica. Na } \\
\text { cozinha brasileira, a cebolinha é muito utilizada em } \\
\text { saladas cruas e como tempero de pratos quentes } \\
\text { como feijão e quiches. }\end{array}$ & $\begin{array}{l}\text { Planta forte, vigorosa, com talos } \\
\text { longos, medindo cerca de } 10 \mathrm{~cm} \text {, } \\
\text { sabor suave e muito agradável. } \\
\text { Ciclo: } 90 \text { a } 100 \text { dias após } \\
\text { semeadura. }\end{array}$ \\
\hline Couve & $\begin{array}{l}\text { É uma planta muito utilizada como verdura na } \\
\text { cozinha, para sopas e conservas entre outros } \\
\text { acompanhamentos. }\end{array}$ & $\begin{array}{l}\text { Planta ereta, vigorosa, com folhas } \\
\text { macias e coloração verde-escura, } \\
\text { tolerante as condições climáticas } \\
\text { adversas. Ciclo: } 60 \text { a } 150 \text { dias após } \\
\text { semeadura. }\end{array}$ \\
\hline Espinafre & $\begin{array}{l}\text { O espinafre é extremamente saudável e ligado a } \\
\text { inúmeros benefícios para a saúde. Comer espinafre } \\
\text { pode beneficiar a saúde dos olhos, reduzir o estresse } \\
\text { oxidativo, ajudar a prevenir o câncer e reduzir os } \\
\text { níveis de pressão arterial. }\end{array}$ & $\begin{array}{l}\text { Pode ser plantada o ano todo em } \\
\text { regiões de verão ameno. cresce até } \\
\text { cerca de } 30 \mathrm{~cm} \text { de altura. Ciclo: } 60 \\
\text { a } 70 \text { dias após semeadura. }\end{array}$ \\
\hline Hortelã & $\begin{array}{l}\text { Uma das plantas mais usadas do mundo. como } \\
\text { tempero em culinária, como aromatizante em certos } \\
\text { produtos alimentares, ou para a extração do seu óleo } \\
\text { essencial }\end{array}$ & $\begin{array}{l}\text { Tolera bem diferentes condições } \\
\text { climáticas, desde que não falte } \\
\text { água. tem alturas variadas em } \\
\text { média de } 25 \mathrm{~cm} \text { até um metro de a, } \\
\text { possui folhas verdes, ovaladas, } \\
\text { rugosas e aromáticas. Ciclo: } 60 \text { a } 70 \\
\text { dias após semeadura. }\end{array}$ \\
\hline Manjericão & $\begin{array}{l}\text { As folhas de manjericão são usadas como um } \\
\text { tempero aromático e também para fazer remédios } \\
\text { caseiros para aftas, tosse e dor de garganta. }\end{array}$ & $\begin{array}{l}\text { apresenta um caule ereto e } \\
\text { ramificado podendo chegar até } 1 \\
\text { metro de altura. Ciclo: } 60 \text { a } 65 \text { dias } \\
\text { após semeadura. }\end{array}$ \\
\hline Pepino & $\begin{array}{l}\text { O pepino é se come geralmente em forma de salada. } \\
\text { O pepino é um diurético natural e de grande ajuda na } \\
\text { dissolução de cálculos renais. Ele é rico em potássio, } \\
\text { que proporciona flexibilidade aos músculos e dá } \\
\text { elasticidade às células que compõem a pele. }\end{array}$ & $\begin{array}{l}\text { Planta forte e vigorosa. Tamanho } \\
\text { aproximado de } 15 \text { x } 5 \mathrm{~cm} \text { e peso } \\
\text { médio de } 180 \text { a } 200 \mathrm{~g} \text {. Ciclo: } 60 \text { a } 70 \\
\text { dias após semeadura. }\end{array}$ \\
\hline
\end{tabular}




\begin{tabular}{|c|c|c|}
\hline Pimenta & $\begin{array}{l}\vec{E} \text { uma das hortaliças mais conhecidas pelos } \\
\text { brasileiros, que a consomem principalmente em } \\
\text { conserva. }\end{array}$ & $\begin{array}{l}\text { As mudas atingem de } 8 \text { a } 10 \mathrm{~cm} \text { de } \\
\text { altura. Ciclo: } 100 \text { a } 120 \text { dias após } \\
\text { semeadura. }\end{array}$ \\
\hline Rabanete & $\begin{array}{l}\text { O rabanete é uma hortaliça consumida no mundo todo } \\
\text { por seu sabor adocicado, refrescante e picante. O } \\
\text { rabanete é uma excelente alternativa para diversificar } \\
\text { a dieta. O uso mais comum é na forma crua, em } \\
\text { saladas. }\end{array}$ & $\begin{array}{l}\text { Planta baixa com folhas de tamanho } \\
\text { médio. Ciclo: } 20 \text { a } 25 \text { dias após } \\
\text { semeadura. }\end{array}$ \\
\hline Salsinha & $\begin{array}{l}\text { A erva pode ser utilizada em saladas, molhos para } \\
\text { todos os tipos de carnes, massas, sopas, pescados e } \\
\text { legumes. A salsinha é um dos temperos mais comuns } \\
\text { da mesa brasileira. Ela é rica em vitaminas } A, B 1, B 2 \\
\text { e } C \text {, além de carregar sais minerais como cálcio, } \\
\text { potássio, fósforo, enxofre, magnésio e ferro. }\end{array}$ & $\begin{array}{l}\text { Planta ereta de tamanho médio. } \\
\text { Possui aroma suave e sabor } \\
\text { agradável. Ciclo: } 70 \text { a } 80 \text { dias após } \\
\text { semeadura. }\end{array}$ \\
\hline $\begin{array}{c}\text { Tomate } \\
\text { cereja }\end{array}$ & $\begin{array}{l}\text { O tomate cereja é uma espécie de tomate cujo } \\
\text { tamanho é menor e seu sabor um pouco mais doce } \\
\text { que um tomate comum. É usado em saladas, enfeites } \\
\text { de pratos ou mesmo ao natural. }\end{array}$ & $\begin{array}{l}\text { O diâmetro varia entre } 3 \text { e } 10 \mathrm{~cm} \text {, e } \\
\text { o formato entre uma esfera e uma } \\
\text { elipse. Ciclo: } 100 \text { a } 120 \text { dias após } \\
\text { semeadura. }\end{array}$ \\
\hline Tomilho & $\begin{array}{l}\text { Normalmente utilizado como condimento, o tomilho } \\
\text { em infusão (mergulhado em água fervente), é usado } \\
\text { no combate a infecções de garganta e pulmonares na } \\
\text { asma e febre dos fenos e na eliminação de parasitas. } \\
\text { Externamente, alivia picadas, dores reumáticas e } \\
\text { infecções fúngicas. }\end{array}$ & $\begin{array}{l}\hat{E} \text { uma planta perene de pequeno } \\
\text { porte, com ramos lenhificados na } \\
\text { base. Ciclo: } 60 \text { a } 65 \text { dias após } \\
\text { semeadura. }\end{array}$ \\
\hline
\end{tabular}

Fonte: Adaptado Agristar (2021).

\subsection{Etapa idealizar}

$\mathrm{Na}$ etapa de ideação, foram geradas as ideias para a construção das hortas verticais sustentáveis. A Figura 5 ilustra o fluxo estimado para a construção das hortas verticais.

Figura 5 - Fluxo para construção das hortas verticais.

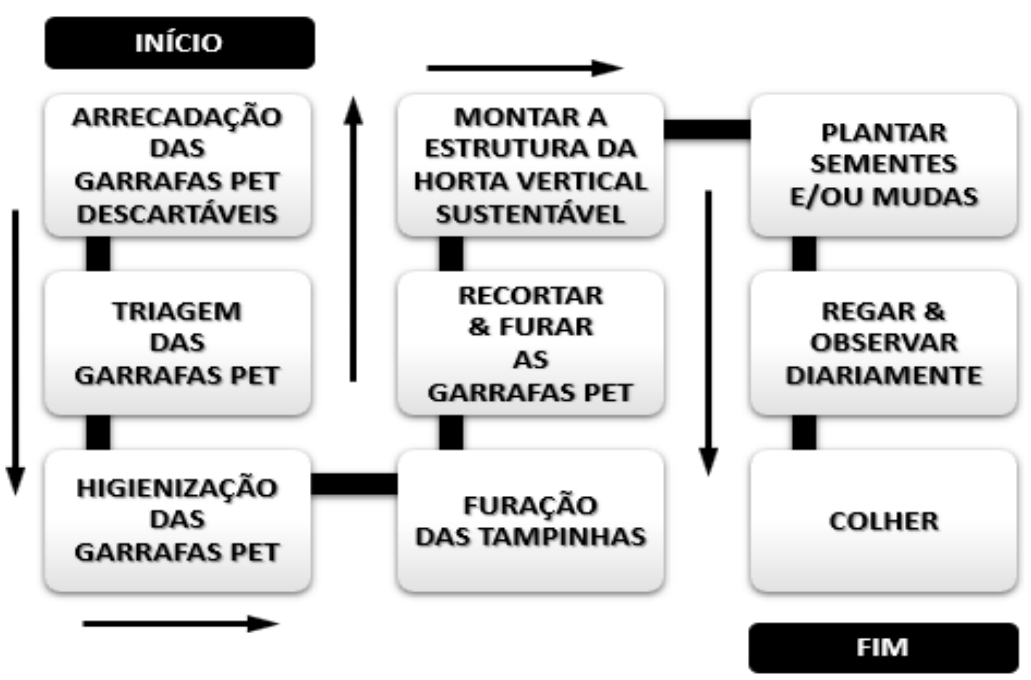

Fonte: Elaborado pelos autores (2021).

A arrecadação das garrafas ocorreu a partir da divulgação do projeto nas redes sociais. A triagem é feita com o objetivo de garantir o bom estado de conservação das garrafas e posteriormente é feita higienização destas. A furação das tampinhas pode ser feita manualmente com uma chave de fenda ou com a utilização de uma furadeira. As garrafas podem ser recortadas com estilete ou tesoura e a estrutura é montada com corda de varal. O plantio e cultivo deve seguir as instruções da embalagem dos fabricantes de sementes. 


\subsection{Etapa prototipar}

$\mathrm{Na}$ etapa de prototipagem as ideias geradas nas fases anteriores para a construção da horta vertical sustentável foram colocadas em prática. Nesta etapa, as ideias são transferidas do âmbito conceitual para a realidade e os protótipos gerados representam de forma física e simplificada, como seriam as hortas verticais ofertadas pelo Projeto de Extensão Universitária da IES. Por se tratar de uma metodologia ágil, a prototipagem permitiu tangibilizar conceitos e auxiliar na redução de custos para a construção das hortas verticais sustentáveis. A Figura 6 ilustra os protótipos gerados pelos grupos para a construção das hortas verticais sustentáveis.

Figura 6 - Protótipos para a horta vertical sustentável.

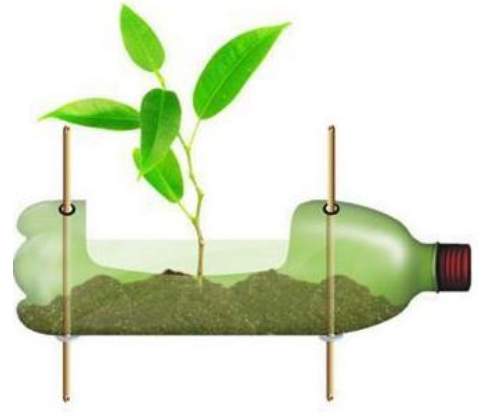

(a)

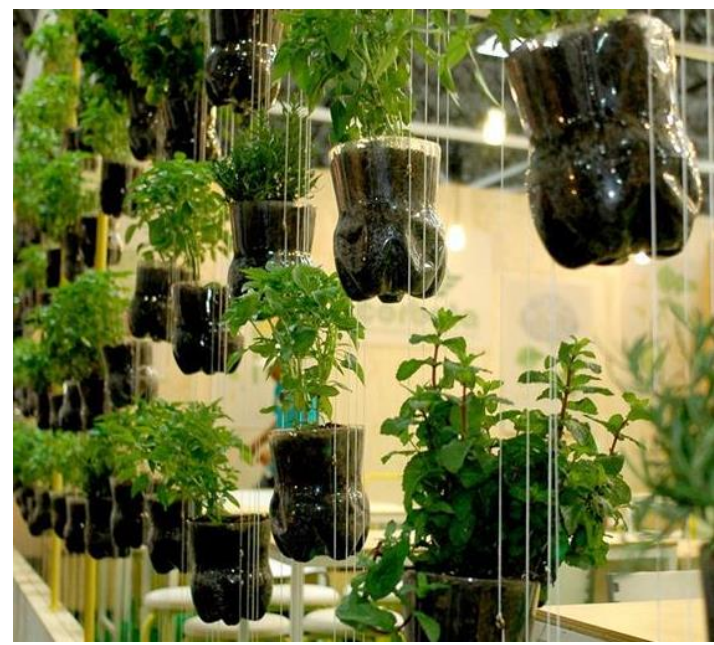

(c)

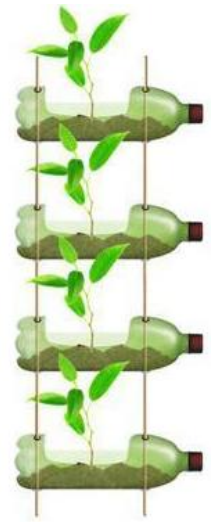

Fonte: Adaptado Artesanato Passo-a-Passo (2021).

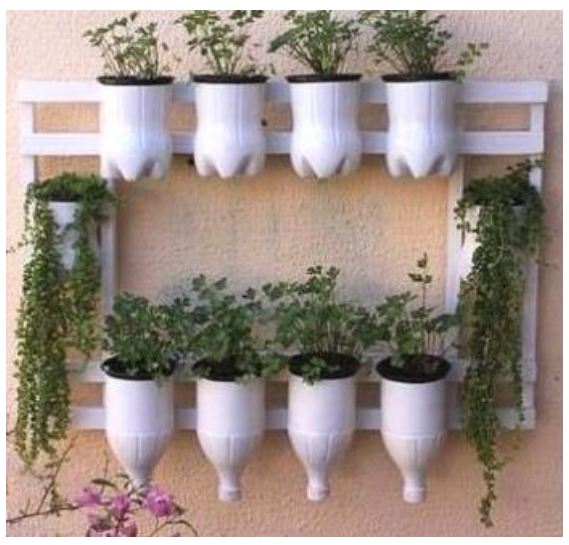

(b)

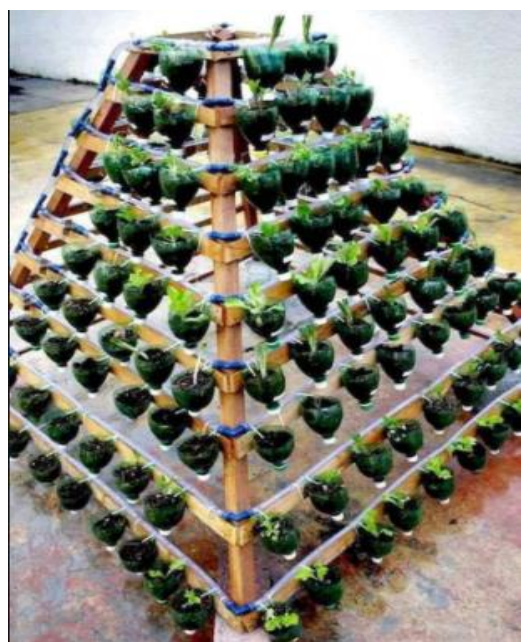

(d)

As hortas verticais sustentáveis apresentam-se como alternativa viável para ambientes pequenos e o processo de montagem apresenta baixa complexidade. Para a etapa de prototipagem, foram sugeridos diferentes modelos para a estruturação da horta vertical sustentável:

a) com a utilização das garrafas PET na posição horizontal com a fixação na parede;

b) com a utilização das garrafas PET na posição vertical com a fixação na parede;

c) com a utilização das garrafas PET suspensas sem a fixação na parede;

d) com a utilização das garrafas PET a partir do piso/chão.

Imagina-se que as hortas verticais se apresentam sempre fixadas em paredes e/ou muros, porém elas podem ser suspensas ou no chão. 


\subsection{Etapa testar}

A fase de testar é a penúltima fase do Design Thinking antes da fase final de implementação. Esta etapa será uma oportunidade para conhecer melhor a percepção das famílias interessadas em receber a horta vertical sustentável com relação aos protótipos apresentados na etapa anterior. Esta etapa tem a sua conclusão prevista para o final do primeiro semestre de 2021. É possível que as equipes utilizem os resultados para redefinir um ou mais problemas adicionais. Dentro dessa abordagem, é possível retornar aos estágios anteriores para encontrar ou descartar soluções alternativas para as hortas verticais. O Produto Mínimo Viável (MVP) pode contribuir como instrumento de aprendizado sobre as hortas verticais sustentáveis em um curto espaço de tempo. O objetivo é buscar a melhor e mais barata versão para a horta vertical sustentável.

\subsection{Etapa implementar}

Uma das dificuldades para a manutenção da horta vertical sustentável é que o cuidado com a terra e irrigação podem variar para muda e/ou sementes utilizadas conforme escrito no Quadro 2. O ciclo de dias necessários entre a semeadura e a colheita das hortaliças podem variar entre 60 e 100 dias, o que requer mais tempo e estudo. A etapa implementar tem por objetivo ofertar o mínimo de 50 hortas verticais sustentáveis às famílias carentes. Observa-se como sucesso para o Design Thinking, a sua capacidade em determinado aspecto da vida do usuário final.

Para administrar os riscos de insucesso na construção e manutenção das hortas verticais, foi elaborado uma matriz de probabilidade e impacto e um plano de respostas aos riscos com ações preventivas e corretivas. A partir do brainstorming realizado com as equipes do projeto, foram estimados os valores de probabilidade e impacto apresentados no Quadro 3 onde observa-se a probabilidade e impacto classificadas em: muito baixo (até $5 \%$ ), baixo (entre 5 e 10\%), moderado (entre 10 e 20\%), alto (entre 20 e 40\%) e muito alta (maior que $40 \%$ ).

Quadro 3 - Avaliação do impacto e probabilidade de riscos para a construção/manutenção da horta vertical.

\begin{tabular}{|c|c|c|c|c|c|}
\hline & $\begin{array}{c}\text { Muito baixa (o) } \\
0,05 \\
\end{array}$ & $\begin{array}{c}\text { Baixa (o) } \\
0,1\end{array}$ & $\begin{array}{c}\text { Moderada (o) } \\
0,2\end{array}$ & $\begin{array}{c}\text { Alta (o) } \\
0,4\end{array}$ & $\begin{array}{c}\text { Muito alta (0) } \\
(0,8)\end{array}$ \\
\hline $\begin{array}{c}\text { Probabilidade } \\
\& \\
\text { Impacto }\end{array}$ & Insignificante & $<10 \%$ & $\begin{array}{c}\text { entre } \\
10 \text { e } 20 \%\end{array}$ & $\begin{array}{c}\text { entre } \\
20 \text { e } 40 \%\end{array}$ & $>40 \%$ \\
\hline
\end{tabular}

Fonte: Adaptado pelos autores (2021).

A análise qualitativa dos riscos teve como objetivo avaliar os tipos e o grau de riscos aos quais a horta vertical estará exposta e qual as ações necessárias para prevenir e/ou mitigar os riscos. Para se chegar ao grau de risco de cada evento sugerido, multiplicou-se a probabilidade pelo impacto conforme resultados apresentados no Quadro 4. Para estimar os riscos, além da opinião de especialistas em hortas, foram consideradas as seguintes técnicas:

$>$ Estimativa análoga: impacto e probabilidade estimados baseado em hortas e plantas/hortaliças cultivadas anteriormente pelos participantes do projeto de hortas verticais sustentáveis;

$>$ Estimativa paramétrica: impacto e probabilidade estimados como possibilidade de ocorrência em mais de uma planta e/ou horta vertical sustentável;

$>$ Estimativa de três pontos: considera os cenários otimista, pessimista e cenário mais provável para as ocorrências na construção e manutenção das hortas verticais sustentáveis. 
Quadro 4 - Itens sugeridos para cultivo na horta vertical.

\begin{tabular}{|c|c|c|c|c|c|c|c|c|}
\hline Risco & $\begin{array}{l}\text { Causas } \\
\text { do risco }\end{array}$ & $\begin{array}{c}\text { Consequências } \\
\text { do risco }\end{array}$ & $\begin{array}{l}\frac{0}{0} \\
\frac{0}{0} \\
\frac{.0}{\overline{0}} \\
\frac{0}{0} \\
\frac{0}{0} \\
\frac{0}{2}\end{array}$ & 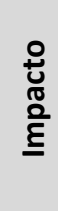 & 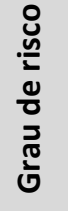 & Descrição & $\begin{array}{c}\text { Resposta } \\
\text { (ações } \\
\text { preventivas) }\end{array}$ & $\begin{array}{c}\text { Plano } \\
\text { contingenci } \\
\text { al (ações } \\
\text { corretivas) }\end{array}$ \\
\hline Planta murchar & Falta de sol & $\begin{array}{c}\text { A planta/hortaliça } \\
\text { morrer }\end{array}$ & 0,2 & 0,8 & 0,16 & Moderado & $\begin{array}{l}\text { Escolher a } \\
\text { posição } \\
\text { apropriada para } \\
\text { tomara apenas o } \\
\text { sol da manhã. }\end{array}$ & $\begin{array}{l}\text { Colocar as } \\
\text { plantas na } \\
\text { sombra em } \\
\text { local seguro } \\
\text { livre de excesso } \\
\text { de sol. }\end{array}$ \\
\hline Planta secar & Excesso de sol. & $\begin{array}{c}\text { A planta/hortaliça } \\
\text { morrer }\end{array}$ & 0,4 & 0,8 & 0,32 & Risco alto & $\begin{array}{c}\text { Escolher a } \\
\text { posição } \\
\text { apropriada para } \\
\text { tomara apenas o } \\
\text { sol da manhã. }\end{array}$ & $\begin{array}{l}\text { Colocar as } \\
\text { plantas na } \\
\text { sombra em } \\
\text { local seguro } \\
\text { livre de excesso } \\
\text { de sol. }\end{array}$ \\
\hline $\begin{array}{c}\text { Planta } \\
\text { secar/murchar }\end{array}$ & Falta de água. & $\begin{array}{c}\text { A planta/hortaliça } \\
\text { morrer }\end{array}$ & 0,2 & 0,8 & 0,16 & Moderado & $\begin{array}{c}\text { Verificar a } \\
\text { frequência } \\
\text { necessária de } \\
\text { regar as plantas. }\end{array}$ & $\begin{array}{c}\text { Colocar as } \\
\text { plantas na } \\
\text { sombra em } \\
\text { local seguro } \\
\text { livre de excesso } \\
\text { de sol. }\end{array}$ \\
\hline $\begin{array}{c}\text { Apodrecer a raiz da } \\
\text { planta por excesso } \\
\text { de água. }\end{array}$ & $\begin{array}{c}\text { Falta de } \\
\text { drenagem (furo) } \\
\text { na garrafa. }\end{array}$ & $\begin{array}{c}\text { A planta/hortaliça } \\
\text { morrer }\end{array}$ & 0,4 & 0,8 & 0,16 & $\begin{array}{c}\text { Risco } \\
\text { moderado }\end{array}$ & $\begin{array}{l}\text { Verificar se a } \\
\text { estrutura possui } \\
\text { e/ou os furos } \\
\text { estão } \\
\text { adequados. }\end{array}$ & $\begin{array}{c}\text { Fazer e/ou } \\
\text { alargar os furos } \\
\text { para a } \\
\text { drenagem do } \\
\text { excesso de } \\
\text { água. }\end{array}$ \\
\hline $\begin{array}{l}\text { Não acontecer a } \\
\text { germinação das } \\
\text { sementes }\end{array}$ & $\begin{array}{l}\text { Processo de } \\
\text { plantio } \\
\text { inadequado. }\end{array}$ & $\begin{array}{c}\text { A planta/hortaliça } \\
\text { morrer }\end{array}$ & 0,4 & 0,8 & 0,16 & $\begin{array}{c}\text { Risco } \\
\text { moderado }\end{array}$ & $\begin{array}{c}\text { Seguir as } \\
\text { instruções de } \\
\text { plantio na } \\
\text { embalagem. }\end{array}$ & $\begin{array}{c}\text { Replantar a } \\
\text { planta e/ou } \\
\text { hortaliça. }\end{array}$ \\
\hline $\begin{array}{l}\text { Apodrecer e/ou } \\
\text { arrebentar as } \\
\text { cordas (varal). }\end{array}$ & $\begin{array}{l}\text { Horta exposta a } \\
\text { intempéries. }\end{array}$ & $\begin{array}{c}\text { Horta cair e } \\
\text { espalhar s }\end{array}$ & 0,2 & 0,2 & 0,04 & $\begin{array}{l}\text { Muito } \\
\text { baixo }\end{array}$ & $\begin{array}{l}\text { Escolher as } \\
\text { cordas } \\
\text { apropriadas e } \\
\text { inspecionar os } \\
\text { nós. }\end{array}$ & $\begin{array}{c}\text { Refazer a } \\
\text { fixação da horta } \\
\text { vertical. }\end{array}$ \\
\hline
\end{tabular}

Fonte: Elaborado pelos autores (2021).

Entre os itens informados no Quadro 2, atualmente estão semeados para a construção das hortas verticais sustentáveis:

$>$ Acelga

$>$ Alecrim

$>$ Alface crespa

$>$ Alaface lisa

$>$ Cebolinha

$>$ Couve

$>$ Espinafre

$>$ Hortelã

$>$ Manjericão

$>$ Pepino

$>$ Pimenta

$>$ Rabanete

$>$ Salsinha

> Tomate cereja 


\section{CONSIDERAÇÕES FINAIS}

Este artigo propôs-se a descrever a aplicação do Design Thinking para a construção de hortas verticais pelos discentes e docentes inscritos no projeto de extensão universitária da IES. Como resultado, conclui-se que a horta vertical sustentável é uma alternativa viável de reutilização para a redução do descarte negligente de garrafas PET no meio ambiente e pode contribuir com ODS \#2 da agenda 2030 da ONU em melhorar a nutrição e promover a agricultura sustentável para as famílias brasileiras. No que tange ao design, as hortas verticais sustentáveis podem servir como decoração e espaço verde em diferentes espaços no ambiente em que forem alocadas.

As limitações apresentam-se com relação ao ciclo de dias necessários entre a semeadura e a colheita das hortaliças que normalmente variam entre 60 e 100 dias. Diante deste cenário, não foi possível concluir as fases de teste e implementação previstas no Design Thinking. Estas fases têm conclusão prevista para o segundo semestre de 2021.

Espera-se que a aplicação do Design Thinking na construção de hortas verticais sustentáveis possa contribuir como prática acadêmica para a formação de profissionais tecnicamente competentes e eticamente comprometidos com a inclusão social, efetivação dos direitos humanos e uma sociedade mais justa e igualitária. Também é esperado que tal prática possa engajar o corpo docente e discentes de diferentes cursos e IES aos Objetivos de Desenvolvimento Sustentável (ODS) da ONU (Agenda 2030).

Como sugestão de realização de trabalhos futuros, sugere-se a complementação deste trabalho com as fases de testar e implementar do Design Thinking e dessa forma, mensurar o grau de aprendizagem dos discentes e docentes envolvidos no projeto. Em suma, sugere-se também a aplicação da metodologia Design Thinking para outros projetos de cunho social preferencialmente alinhados com os ODS previstos na Agenda 2030 da ONU.

\section{Agradecimentos}

Os agradecimentos à IES pelo apoio e incentivo a pesquisa, seu corpo docente, administração e coordenação. Os agradecimentos aos colegas que colaboraram direta ou indiretamente com a realização deste trabalho. 


\section{REFERÊNCIAS}

AGRISTAR. Ficha técnica de sementes. Disponível em:

https://agristar.com.br/topseed/default.asp Acesso em: 03 abr. 2021.

ARTESANATO PASSO-A-PASSO. Horta em garrafa PET: como fazer passo para montar sua horta, 2020. Disponível em:

https://www.artesanatopassoapassoja.com.br/horta-em-garrafa-pet/ Acesso em: 05 abr. 2021.

BRASIL. Lei ㄲo 13.005/2014, resolução no. 7, de 18 de dezembro de 2018. Diário Oficial da União, Ministério da Educação, Brasília, DF. Disponível em:

https://www.in.gov.br/materia/-/asset publisher/Kuirw0TZC2Mb/content/id/55877808

Acesso em: 05 abr. 2021.

BRENNER, Walter.; UEBERNICKEL, Falk (ed.). Design Thinking for Innovation: Research and Practice, Springer, 2016.

CNS. Sobre ações de enfrentamento ao Coronavírus: Recomendação ํo 027 de 22 de abril de 2020. Ministério da Saúde, Brasil. Disponível em:

http://conselho.saude.gov.br/recomendacoes-cns/1132-recomendacao-n-027-de-22-deabril-de-2020. Acesso em: 28 out. 2020.

DONTHU, Naveen; GUSTAFSSON, Anders. Effects of COVID-19 on business and research. Journal of Business Research, v. 117, p. 284, 2020.

HEHN, Jennifer; MENDEZ, Daniel; UEBERNICKEL, Falk; BRENNER, Walter; BROY, Manfred. On Integrating Design Thinking for Human-Centered Requirements Engineering. IEEE Software, v. 37, n. 2, p. 25-31, 2019.

IDEO. Design Thinking for Educators. 2 ed., Toolkit, 2012.

Inquérito Nacional sobre Insegurança Alimentar no contexto da pandemia da COVID-19 no Brasil Disponível em: http://olheparaafome.com.br/ . Acesso em: 05 abr. 2021.

OMS et al. Coronavirus disease 2019 (COVID-19): situation report, 72. 2020.

Disponível em: https://www.who.int/docs/default-source/coronaviruse/situationreports/20200311-sitrep-51-covid-19.pdf?sfvrsn=1 ba62e57 10 . Acesso em: 28 out.2020. 


\section{SOCIAL DESIGN THINKING APPLIED TO PRODUCTION ENGINEERING TEACHING}

Abstract: Due to COVID-19 pandemic, global population faced an emergency and about this context, World Health Organization (WHO) has declared pandemic in March 2020 and, according to their orientations, Brazilian National Health Council (CNS) recommended social isolation actions in order to avoid the spread of the virus. On this matter, Brazilian population was affected at all, configuring what we now call as "New Standard". Before this scenario, hungry took place among poorer Brazilian families (those ones with lower per capita income), bringing some level of food insecurity for more than a half of the Brazilian homes. $B y$ the other hand, discussion around initiatives to fight hunger has been done, even if insufficiently, inside Universities. From initial considerations on, this article proposes to describe Design Thinking application to make vertical vegetable gardens by the students and teachers enrolled to the project of University Extension. In order to achieve the proposed objective, a sustainable vertical vegetable garden construction case study was carried out, where Design Thinking Methodology was applied. These gardens will be offered to vulnerable families. The expectation is that the information generated on this article can contribute as an incentive for sustainable agriculture, as defined at the sustainable development objective \#2 from UN 2030 Agenda. It is suggested the replication of this initiative for other courses offered by the University, as well as for other, public or privet, institutions.

Keywords: Engineering Teaching. Sustainable Agriculture. Zero Hunger. Vertical vegetable gardens. Social responsibility. 